Review

\title{
A Bibliometric and Visual Analysis of Rural Development Research
}

\author{
Ying Lu* and Walter Timo de Vries
}

check for

updates

Citation: Lu, Y.; de Vries, W.T. A Bibliometric and Visual Analysis of Rural Development Research. Sustainability 2021, 13, 6136. https:// doi.org/10.3390/su13116136

Academic Editor: Vida Maliene

Received: 29 April 2021

Accepted: 25 May 2021

Published: 29 May 2021

Publisher's Note: MDPI stays neutral with regard to jurisdictional claims in published maps and institutional affiliations.

Copyright: (c) 2021 by the authors. Licensee MDPI, Basel, Switzerland. This article is an open access article distributed under the terms and conditions of the Creative Commons Attribution (CC BY) license (https:// creativecommons.org/licenses/by/ $4.0 /)$.
Chair of Land Management, Department of Aerospace and Geodesy, Technical University of Munich (TUM), 80333 Munich, Germany; wt.de-vries@tum.de

* Correspondence: ying.lu@tum.de

\begin{abstract}
Rural development research integrates numerous theoretical and empirical studies and has evolved over the past few decades. However, few systematic literature reviews have explored the changing landscape. This study aims to obtain an overview of rural development research by applying a bibliometric and visual analysis. In this paper, we introduce four computer-based software tools, including HistCite ${ }^{\mathrm{TM}}$, CiteSpace, VOSviewer, and Map and Alluvial Generator, to help with data collection, data analysis, and visualization. The dataset consists of 6968 articles of rural development research, which were downloaded from the database Web of Science. The period covers 1957 to 2020 and the analysis units include journals, categories, authors, references, and keywords. Co-occurrence and co-citation analysis are conducted, and the results are exported in the format of networks. We analyze the trends of publications and explore the discipline distribution and identify the most influential authors and articles at different times. The results show that this field of study has attracted progressively more scholars from a variety of research fields and has become multidisciplinary and interdisciplinary. The changing knowledge domains of rural development research also reflect the dynamics and complexity of rural contexts.
\end{abstract}

Keywords: rural development research; bibliometric analysis; visualization

\section{Introduction}

Over the past few decades, there have been numerous attempts at defining, describing, unpacking, and dissecting the concept of "rural development". According to the World Bank Sector Paper on Rural Development, "Rural Development is a strategy designed to improve the economic and social life of a specific group of people-the rural poor [1]". Chambers makes a complementary explanation on this definition, pointing out that "the group includes small-scale farmers, tenants and the landless" [2]. Copp identifies "rural development" as a "policy goal" [3], while Harris argues that it may also "refer to processes of change in rural societies, not all of which involve action by the government" [4]. Van der Ploeg et al. claim that rural development should be recognized as "a multi-level, multi-actor and multi-faceted process" [5].

Rural development has been widely discussed both in the academic field and by governments and NGOs. However, there is no comprehensive and universally acknowledged definition of it, taking account of the diverse disciplines it involves and the divergent contexts in which it is embedded. The concept "rural" can be defined from various dimensions. It can be distinguished from "urban" based on the spatial characteristics, the functions, or the cultural identity [6]. The term "development" can also be interpreted differently. Hence, rural development research involves a range of disciplines, including agriculture, economy, sociology, environmental studies et al. [7]. Researchers with specific academic backgrounds tend to define problems and seek solutions from different perspectives, and that is why a consensus on the definition can never be reached. Besides, the diversity of research objects must be taken into consideration. The research areas of rural development studies are 
distributed all over the world, where the socio-economic, environmental, and political contexts vary dramatically. There are also significant differences between stakeholders in different case studies. Moreover, rural contexts have evolved. Both the society and environment in rural areas have witnessed fundamental changes in the process of globalization and urbanization. The development of science and technology also contributes to the dramatic transformation in rural areas. The application of agricultural machinery has cut labor costs, while advanced mobility and communication technology has changed the lifestyles of rural people.

As rural development research integrates numerous theoretical and empirical studies, there has been a growing realization in recent years that it would not be possible to generate a widely accepted definition of "rural development" [5]. We argue that it could be more desirable and feasible to conduct a systematic literature review and explore the changing landscape of rural development research overtime than to focus on formulating a single definition. This literature review aims to obtain a wide-ranging and longitudinal overview of rural development research. It could help scholars to find the research frontier and gaps in rural studies. Furthermore, the changes in the knowledge domain through time reflect not only the transformation of the economics, environment, and societies in rural areas, but also the shifting concerns of different stakeholders including scholars, local governments, and international organizations.

The thematic and chronological analysis has been applied by several scholars in literature reviews concerning rural development. Ellis and Biggs (2001) draw a rural development ideas timeline from the 1950s to 2000s, which contains a variety of terms that are claimed to influence rural development thinking [8]. The terms vary from development approaches such as "transformation approach" and "sector-wide approach" to processes or phenomena such as "growth role of agriculture" and "rise of NGOs". Some development goals such as "poverty alleviation" and "good governance" as well as problems such as "urban bias" are also included. Phuhlisani explores the international ideas and approaches to rural development from the 1950s to the 2000s. Different approaches are periodized by decades. For example, the 1960s are associated with "modernization approaches" and the 1970s with "large-scale state development interventions". "Market liberalization" is summarized for the 1980s, while "participation and empowerment" for the 1990s. Diverse approaches occur in the 2000s, including "poverty eradication", the "reinvigoration of smallholder agriculture", "sustainable farming systems" and "the location of producers within global value chains". This paper explains each approach in detail by introducing the ideas from both articles by leading scholars and documents from international organizations such as the United Nations and the World Bank [9]. These two papers provide overviews of the evolving themes in rural development studies and summarize the ideas and approaches in chronological order. However, they both lack a proper explanation of methods, processing procedures, and criteria of how these terms have been chosen, so that their representativeness cannot be verified. Hence, we carry out a complementary study by conducting a systematic literature review of rural development research with quantitative methods.

Literature can be treated as datasets, which contain various pieces of information such as titles, publication years, authors, journals, keywords, and references. Different studies are interrelated by sharing identical information and citations. We suggest that the intellectual structure of rural development research can be identified through the quantitative analysis of this information and its interrelations. Due to the vast number of publications and the massive amount of data they contain, it is inefficient and even impossible to undertake a manual collection and compilation. Thanks to the online literature database and programming techniques, we can use software-supported methods in the systematic literature review. In this study, we perform a bibliometric and visual analysis of rural development research. The aim is to explore the knowledge domain and its evolution through time and demonstrate the results visually. This paper is organized in the following order. In Section 2, the theoretical background of the bibliometric and visual 
analysis is introduced. Then, we present the methodological steps and the software tools which we employed in this paper. The empirical results are demonstrated and interpreted with figures and tables in Section 3, including the results of the yearly output, the journal co-citation analysis, the category co-occurrence analysis, the author co-citation analysis, the reference co-citation analysis, and the keyword co-word analysis. Interesting findings and their implications are further discussed in Section 4.

\section{Materials and Methods}

We introduce two methods, bibliometric analysis, and science mapping, in this paper to perform the quantitative and visual analysis of rural development research. Figure 1 presents the methodological steps of this study. There are three major procedures, including data collection, data analysis, and visualization. Each procedure contains several steps. Four software tools, including HistCite ${ }^{\mathrm{TM}}$, CiteSpace, VOSviewer, and Map and Alluvial Generator, are employed at different steps of our research. The limitation of this study is introduced at the end.

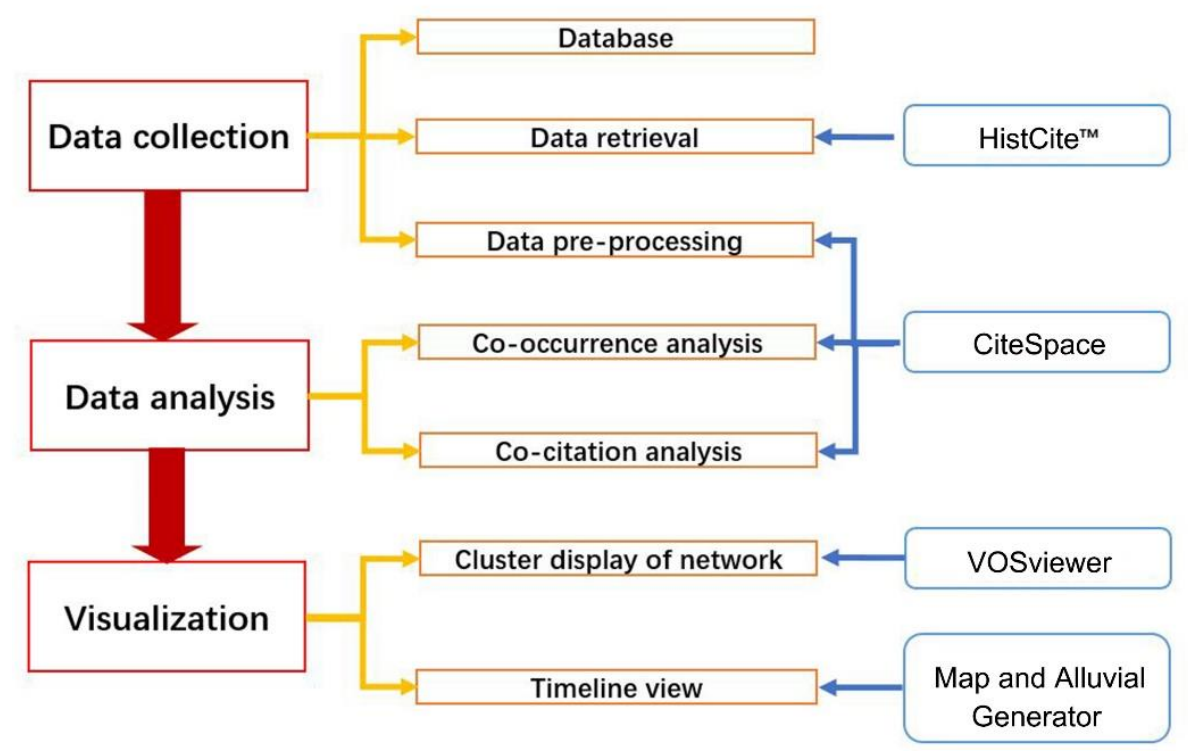

Figure 1. Methodological steps of the research.

\subsection{Bibliometric Analysis}

The terminology "bibliometrics" was coined in 1969 by Pritchard, replacing the former term "statistical bibliography" and is defined as the "application of mathematics and statistical methods to books and other media of communication [10]". Fairthorne (1969) extends the scope of this concept and describes it as the "quantitative treatment of the properties of recorded discourse and behavior appertaining to it [11]". Since then, several scholars have given diverse definitions [12-15]. The common idea shared by these scholars is that bibliometrics involves performing "quantitative analysis" to study "publications" and "written communications". Pritchard points out that the purpose of bibliometric is "to shed light on the processes of written communication and of the nature and course of development of a discipline" [10]. White and McCain claim that its task is to "provide evolutionary models of science, technology, and scholarship" [16]. Various tools and indicators of bibliometrics have been developed to detect publication patterns, to analyze the citation network, and to illustrate the emerging trends and new topics of certain scientific disciplines [17-20].

Bibliometric analysis has also been applied in many research fields of natural and social sciences. Liao et al. study the status of medical big data through bibliometrics and visualization analysis [21]. Wang and Liu conduct a bibliometric analysis of rural studies by collecting data of 4655 articles from 1990 to 2012. In that paper, the discipline that has 
been studied is "rural geography" and articles are limited to only five specific research fields [7]. To conduct a more comprehensive study, the methods in this paper are applied in different ways.

\subsection{Science Mapping}

It has been argued that literature with information about titles, publication years, authors, journals, keywords, and references can be related to each other and form large networks. Science mapping, as a supported procedure of bibliometrics, provides a spatial representation of the structures of these networks. Maps that describe how the literature is intellectually connected may allow us to view the relationships and developments of knowledge clearly and discover something that is hidden in statistics [22]. Small designs the general framework for the bibliometric analysis and explores new methods of creating large-scale maps, which contain thousands of documents and citation data [23]. After that, numerous methods and techniques of science mapping have been proposed. With the rapid development of computer science, several software tools have been designed. Cobo et al. carry out a cooperative study of these software tools and give instructions about how to choose them for different purposes [24].

\subsection{Software Tools}

In this paper, we introduce four computer-based software tools: HistCite ${ }^{\mathrm{TM}}$, CiteSpace, VOSviewer, and Map and Alluvial Generator. With diverse specialization in bibliometric analysis and science mapping, these software tools are employed in different stages of analysis in our study.

HistCite $^{\mathrm{TM}}$ is a freely available software tool used for bibliometric analysis. The name of this program comes from the initial purpose of the developers, which was to study citation-based historiography [25]. It was designed by Eugene Garfield and his associates in the early 2000s and can be downloaded from the website of Clarivate Analytics at https:/ / support.clarivate.com/ScientificandAcademicResearch/s/article/HistCiteSystem-requirements?language=en_US (accessed on 10 May 2018). This program has strong advantages in detecting the citation relationships of publications and identifying the most significant ones by calculating the citation scores. The analysis results are presented in tables, ordered by publication years, authors, languages, countries, or citation frequency. HistCite $^{\mathrm{TM}}$ is employed in this paper for the complement of the original dataset.

CiteSpace is a Java-based application for analyzing and visualizing the emerging trends and patterns in a knowledge domain of scientific publications [19]. Prof. Chen at Drexel University developed it in 2004 and has continued updating new versions frequently since then. It can be freely downloaded at http://cluster.cis.drexel.edu/ cchen/citespace/ (accessed on 17 June 2020). CiteSpace provides network analysis and burst detection, using bibliographic information of publications. Different networks can be constructed, for example, the network of co-occurring categories and keywords and the network of co-citation references and journals. Besides, there are several other functions in CiteSpace that are available for bibliometric analysis. For example, we use the "duplicate elimination" function to process the dataset.

VOSviewer is also a software tool for building and visualizing bibliometric networks. It was developed by van Eck and Waltman from the Centre for Science and Technology Studies at Leiden University. It is also a free program and every few months a new version is made available online at http: / / www.vosviewer.com (accessed on 25 November 2020). VOSviewer specializes in the graphical representation of bibliometric maps [24]. It provides different ways to display networks and allows us to closely examine a map by the zoom, scroll, and search functions [26]. Moreover, by dealing with a large number of items, the cluster display can give us a clear overview of the network structure. Thus, VOSviewer is employed in this paper mainly to generate a better visualization of networks.

Map and Alluvial Generator are two web applications developed by Rosvall and Bergstrom in 2008. They are available at http:/ / www.mapequation.org/apps.html (ac- 
cessed on 25 January 2020). Map Generator can be used to illustrate a network at a certain time point. Then, other networks at different time points can be loaded in chronological order. In Alluvial Generator, changes between those networks can be detected, and a timeline view can be presented, revealing the structural transformation of networks $[27,28]$.

\subsection{Data Collection}

Data collection in our study means gathering useful information from the relevant literature and form a dataset, which is prepared for further analysis. It is achieved in four steps, including choosing the database, making a search strategy, data retrieval, and data pre-processing.

\subsubsection{Database}

Diverse bibliographic databases that contain various types of publications are available online nowadays. Google Scholar, ScienceDirect, Web of Science, and some other databases are all widely used among scholars from different scientific fields. In this research, we chose Web of Science (WoS) as the data source for further bibliometric analysis for the following two reasons. Firstly, WoS is considered to have comprehensive coverage of the leading journals and influential publications worldwide. Secondly, the determining reason for choosing WoS is that the format of publications that can be downloaded from this database can be directly read by the software tools that we introduced above. From this point of view, WoS has an advantage over other databases.

\subsubsection{Search Strategy}

The search term "rural development" is used as the keyword in a topic search, which means the publications which contain the enclosed phrase "rural development" in their titles, abstracts, and keywords are collected. As we intend to explore the whole landscape of rural development research, publications in all subject categories are included. The timespan starts from 1900, the earliest year that can be chosen in WoS, and ends in 2020. The document types include articles, proceedings papers, reviews, book chapters, editorial materials, and others. The retrieval documents in this paper are restricted to articles because they normally contain information such as keywords and references, which are essential for bibliometric analysis. Following this search strategy, a total number of 6273 articles with 214,161 cited references are found, written by 13,699 authors, and published in 1455 journals. We build the preliminary dataset DatasetRD with these 6273 records.

\subsubsection{Data Retrieval}

The main defect of using a keyword-based search strategy lies in the incompletion of the dataset. Some important and influential articles in this field may not be included, simply because the phrase "rural development" does not appear in the titles, abstracts, or keywords of these articles. Thus, an extra retrieval process is necessary. In this research, we use the HistCite ${ }^{\mathrm{TM}}$ program to examine the highly cited references in DatasetRD. The citation count of these 214,161 references varies from 1 to 191, of which 2046 articles have a citation count of more than 6 (from 7 to 191). We consider that these articles are also relevant items that should be added to the dataset. Eventually, 877 articles that are not initially included in DatasetRD and can also be retrieved in WoS. These articles make up the complementary dataset DatasetPLUS.

\subsubsection{Data Pre-Processing}

Errors in the datasets are not evitable. Duplicates and misspelling are the common errors in the datasets that contain bibliographic information. Detecting these errors through pre-processing is essential to improve the quality of datasets and analysis results [24]. After the combination of DatasetRD and DatasetPLUS, we employ CiteSpace to eliminate the duplicate and examine all items to see if they can be recognized in the software tool 
correctly. Finally, we make the dataset DatasetALL, which contains 6968 unique articles, and use it for further analysis.

\subsection{Data Analysis}

In our research, two functions in CiteSpace are employed for data analysis: cooccurrence analysis and co-citation analysis. The analysis units include journals, categories, authors, references, and keywords. A co-occurrence relationship is defined between two units when appearing together in one article. We perform the category co-occurrence analysis and keyword co-word analysis based on this method. If two units appear simultaneously in the reference list of an article, they are defined as co-cited. Journal co-citation analysis, author co-citation analysis, and reference co-citation analysis are applied in this research.

The outputs of analysis are in the form of networks, which can be visualized in VOSviewer and Alluvial Generator for further analysis. The parameter $\mathrm{k}$ in CiteSpace is set as 1 in all analyses except the reference co-citation analysis, to control the size of the networks. There are two important indicators from the analysis results: Count and Centrality. The number of Count represents the co-occurrence or co-citation frequency of one unit. The value of Centrality of a unit is determined by its connections with other units. The unit with a higher Count and Centrality value can be identified as an important and influential unit in the network.

\subsection{Visualization}

The networks generated in CiteSpace are imported in VOSviewer for visualization. The cluster display is applied in our research to have a better structural view of the networks. In a map, each unit is presented as a node. It can be a journal, a category, an author, an article, or a keyword. The size of each node is proportional to the degree of centrality, which is calculated in CiteSpace. The distance between the nodes shows their relationship. If two nodes are displayed near to each other, it can be interpreted that they are strongly related. Links represent the direct co-occurrence and co-citation. The strength of the links is proportional to the co-occurrence or co-citation frequency. In our research, to achieve a better display, only the largest nodes and strongest links are demonstrated in the maps. Nodes related to stronger links can be grouped into one cluster, and each cluster is assigned one color. It can be interpreted that the units within a cluster share a high homogeneity, while the units in different clusters are heterogeneous. With the cluster display, we can identify the intellectual structure of rural development research from several perspectives [24].

We employ Alluvial Generator for the chronological analysis. Category co-occurrence and author co-citation analysis are carried out in CiteSpace and the period of the analysis is set as every five years. The articles from before 1971 do not adequately form a network. Therefore, the beginning year is set at 1971 . Ten networks are exported from each analysis and then imported in Alluvial Generator. The changes in the centrality of nodes can be detected, and a timeline view from 1971 to 2020 is generated.

\subsection{Limitations}

DatasetALL consists of articles that are downloaded from the Web of Science. Using a single database causes some limitations of this study. First, there are many influential articles in this research field that are not included in the database of WoS. For example, the article "Socialism and Rural Development" [29], written by Nyerere in 1967, is an important paper concerning rural development in Africa. The author describes how the system of socialism has changed how traditional families live in Tanzania. Furthermore, the document type of our dataset is restricted to "article". Books that are highly cited are not shown in the results and their authors who provide foundational theories are not identified. Most importantly, a large number of publications cannot be processed because of their languages. Since we use the English search words "rural development" in WoS, 
more than $95 \%$ of the articles we find are written in English. It means that most of the articles concerning rural development in Latin America, Africa, and Asia that are written in Spanish, French, Chinese, etc. are not included in our dataset. Hence, the results of this study cannot represent the viewpoint of some local researchers from those nonEnglish-speaking countries. To sum up, our analysis cannot cover every crucial publication concerning rural development, but we believe that the results allow us to have reliable insight into the knowledge domain through time.

\section{Results}

In this section, the empirical results of this research are presented in detail. First, we analyze the trends of publications. Then, we present the results of journal co-citation analysis and category co-occurrence analysis to explore the discipline distribution. The most influential authors and references at different times are identified in Sections 3.4 and 3.5. The results of keyword co-word analysis and burst detection are demonstrated in Section 3.6, which reveal the knowledge domain of rural development research.

\subsection{Article Outputs}

Figure 2 plots the yearly output of articles from the DatasetALL. Based on the changes in the number of articles, three stages of development of this research field can be identified.

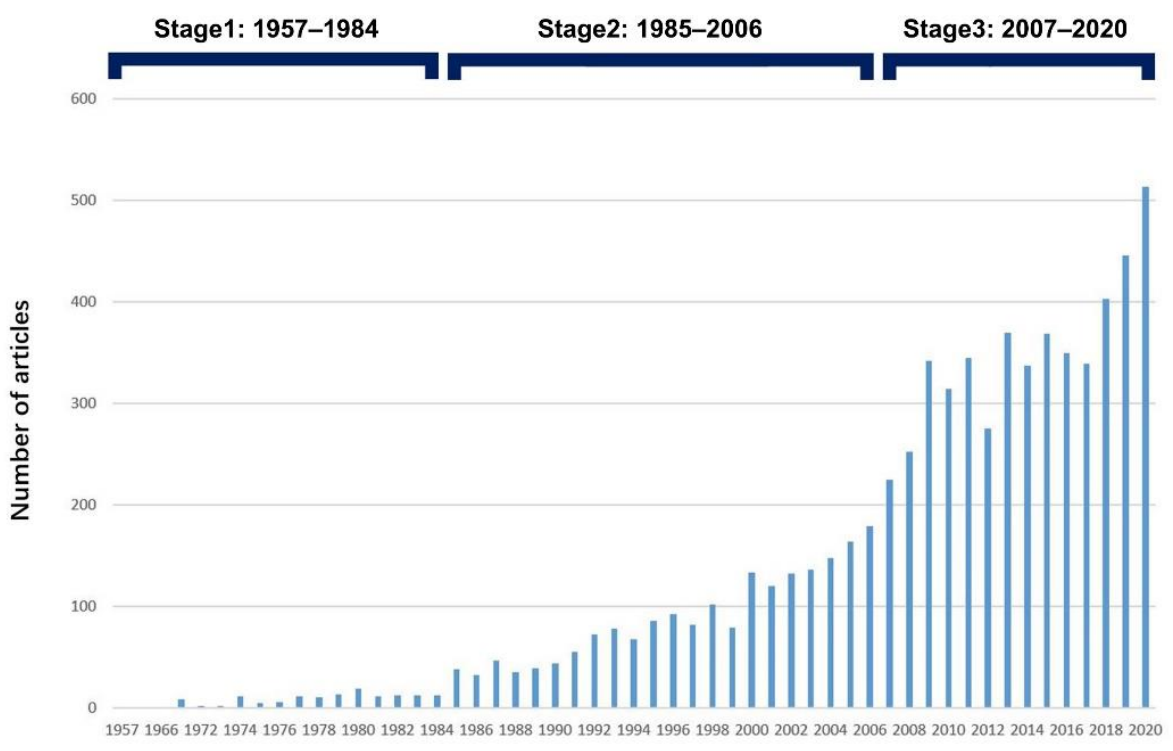

Figure 2. Yearly output of articles from 1957 to 2020.

The first stage lasts from 1957 to 1984 . The first article in DataALL is published in 1957. After that, the number shows no significant increase in the following years, and the annual output is around 10. In this period, the research has not yet fully developed. It is until 1985 that the continuous growth can be observed from Figure 2. One of the reasons to explain this phenomenon could be that two of the most important journals were first published at that time. Land Use Policy, issued in 1985, and the Journal of Rural Studies, issued in 1984 have provided significant platforms for researchers to discuss various topics concerning rural development. The number of articles then increased continuously from 38 in 1985 to 179 in 2006. The third stage begins in 2007, with an explosive increase in the yearly output. During the last decade, the number of annually published articles stays around 350 and reaches a peak of 513 in 2020.

During the past few decades, urbanization has been identified as a global phenomenon, which has had far-reaching effects on the social, economic, and environmental development of human societies. In 2020,56.2\% of the world's population lived in urban areas, and it is estimated that the number will reach $60 \%$ by 2030 [30]. However, the rural areas have 
never become less important or received less attention from scholars in the rapid process of urbanization. The increasing number of articles shows rural development has always been and still will be a crucial issue in multiple academic fields, which implies a promising future for rural development research.

\subsection{Journal Co-Citation Analysis}

Rural development research can be found in a wide variety of journals. The articles from DatasetALL contain 234,689 references, which are published in more than 35,000 journals and conferences. As explained in the methodology section, the journal co-citation analysis examines the co-citation frequency of journals. The journals with the highest count and centrality degree can be identified as the most influential journals in this research field. The result consists of 133 nodes with 615 links. Table 1 lists the top 10 journals, along with the citation count, centrality, impact factor in 2019, and the cluster number.

Table 1. Top 10 highly cited journals.

\begin{tabular}{|c|c|c|c|c|c|}
\hline & Journal & Count & Centrality & $\begin{array}{l}\text { Impact Factor } \\
\text { in } 2019\end{array}$ & Cluster No. \\
\hline 1 & Journal of Rural Studies & 1710 & 0.22 & 3.544 & $\mathrm{~J} 4$ \\
\hline 2 & World Development & 1494 & 0.37 & 3.869 & $\mathrm{~J} 6$ \\
\hline 3 & Sociologia Ruralis & 1178 & 0.07 & 2.540 & $\mathrm{~J} 4$ \\
\hline 4 & Land Use Policy & 1054 & 0.07 & 3.682 & $\mathrm{~J} 5$ \\
\hline 5 & Environment and Planning $A$ & 706 & 0.04 & 3.033 & $\mathrm{~J} 2$ \\
\hline 6 & Ecological Economics & 690 & 0.14 & 4.482 & $\mathrm{~J} 1$ \\
\hline 7 & American Journal of Agricultural Economics & 684 & 0.12 & 2.532 & $\mathrm{~J} 3$ \\
\hline 8 & Science & 647 & 0.02 & 41.845 & $\mathrm{~J} 1$ \\
\hline 9 & Geoforum & 641 & 0.04 & 3.098 & $\mathrm{~J} 2$ \\
\hline 10 & Journal of Environmental Management & 621 & 0.04 & 5.647 & $\mathrm{~J} 1$ \\
\hline
\end{tabular}

The Journal of Rural Studies ranks first with 1710 citation counts. It is a comprehensive journal, which publishes research in social science disciplines, including geography, sociology, economics, and planning et al. The journal contributes to a better understanding and analysis of rural issues all around the world. World Development, a multidisciplinary journal, with 1494 counts, occupies the second position. The highest centrality degree indicates the predominance of this journal over decades. The articles in it concentrate on the studies of development processes, which occur in various places, involve different levels, and are shown in diverse ways. This journal aims to offer a communicational platform for international cooperation. The journal Sociologia Ruralis ranks third and mainly focuses on European rural development, especially in the fields of sociology, policy, and culture. Other influential journals include Land Use Policy, Environment and Planning A, American Journal of Agricultural Economics et al.

Figure 3 presents the journal co-citation network with 106 closely connected nodes and 150 links. The journals are classified into 8 clusters, which are illustrated with different colors. Cluster J1 (blue) is the largest cluster and is located at the bottom left of the map. There are 26 journals in this cluster, including Science, Nature, Ecological Economics, Agriculture Ecosystems and Environment, Journal of Environment Management et al. It can be observed from the names of the journals that cluster J1 mainly focuses on the rural ecology and environmental sciences. Cluster J2 (purple) and cluster 4 (red) are closely related to each other and contain journals such as the Journal of Rural Studies, Sociologia Ruralis, Rural Sociology, Environment and Planning A, and Geoforum et al. These journals pay close attention to the social and geographic aspects of rural issues. In the middle of the map lies cluster J5 (cyan), which connects the clusters on the left and right sides. Land Use Policy, Habitat International, Landscape and Urban Planning, Cities, and Urban Studies are included in it. Cluster J3 (yellow) and Cluster J8 (green) contain several journals related to Agriculture, for example, the American Journal of Agricultural Economics, Agricultural System 
and Food Policy. Cluster J6 (orange) is on the top of the map. The major journals in it include World Development, Economic Development and Cultural Change, Population Development and Review et al. This cluster is oriented towards development studies.

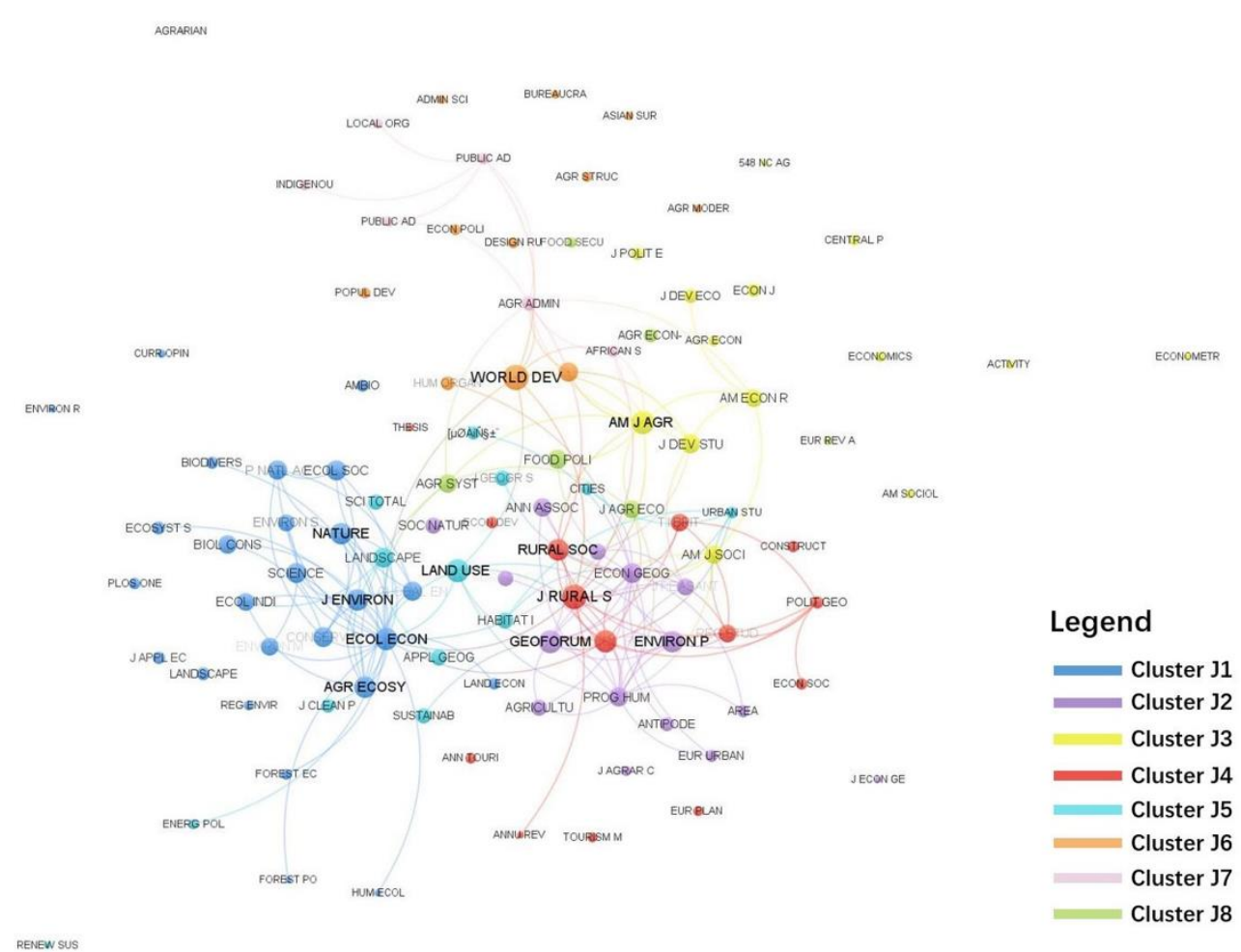

Figure 3. Journal co-citation network.

Each cluster in Figure 3 represents a group of journals that share a similar research orientation within rural development studies. The clusters on the left side display a stronger association with natural science, while the clusters on the right are more related to social science. The journals at the interface belong to the disciplines inbetween. The result indicates the complexity of rural development research, which has drawn the attention of researchers from different academic fields. To have a more accurate overview of the disciplines involved, we conduct the category co-occurrence analysis.

\subsection{Category Co-Occurrence Analysis}

Subject categories can tell us from which disciplinary perspectives rural development is studied. According to the classification system of Web of Science, every journal is assigned to two or more Web of Science Categories and Research Areas. The articles published in one journal share the same information of Categories and Research Areas. For example, Journal of Rural Studies is assigned to Geography, Public Administration, and Planning and Development, while Land Use Policy belongs to Environmental Sciences and Ecology and Environmental Studies.

Category co-occurrence analysis detects the disciplinary distribution of rural development research by identifying the major categories and their interrelationships. The 6968 articles in DatasetALL cover distinct Categories and Research Areas. The network exported from CiteSpace contains 66 nodes with 320 links. Figure 4 illustrates the closely connected 61 nodes with 100 links. 


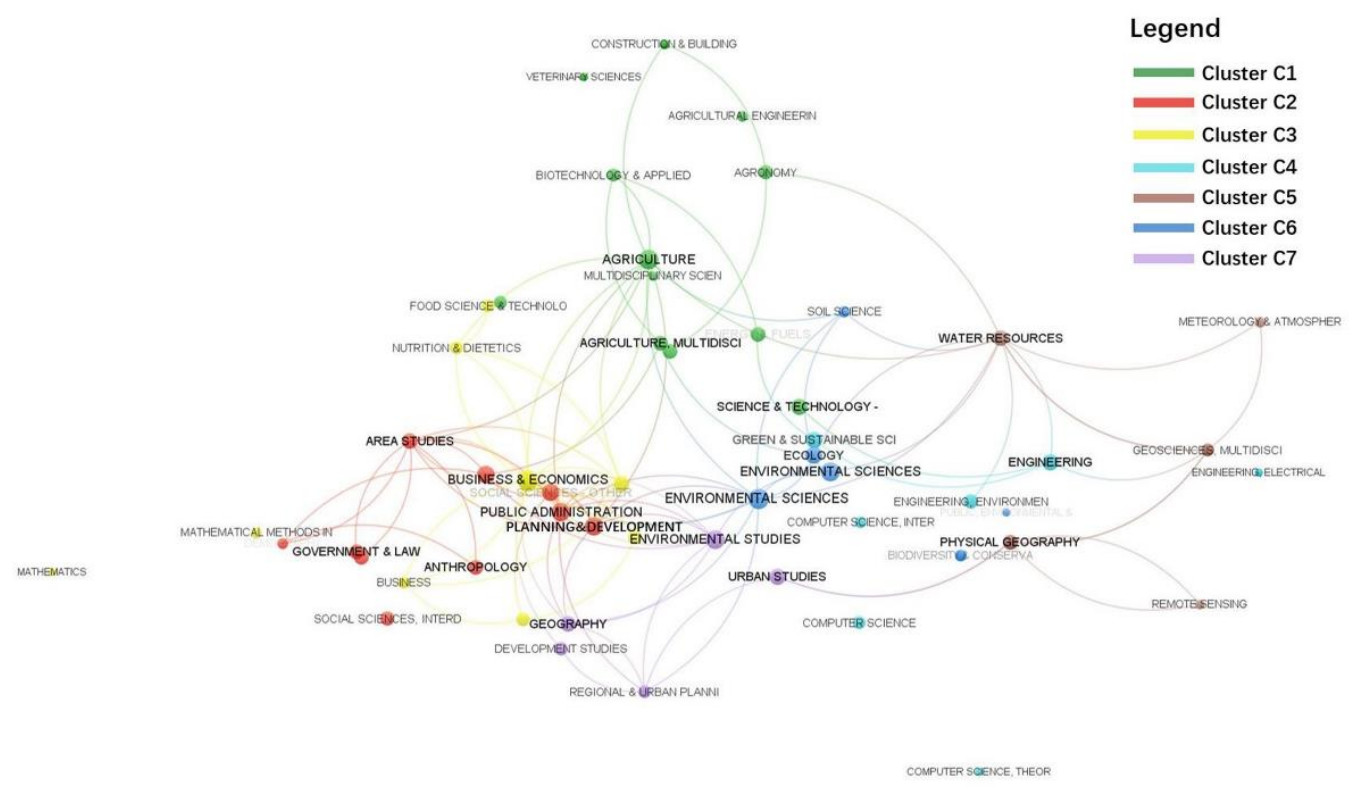

Figure 4. Category co-occurrence network.

The 61 categories are grouped into 7 clusters based on their connections. The top 30 categories with the highest co-occurrence count are listed in Table 2 . With a centrality degree of 0.38 , Agriculture is identified as the most significant category which has the strongest connections with other categories. Categories related to Agriculture including Forestry and Agronomy make up cluster C1 (green). Cluster C2 (red) contains Public Administration, Planning and Development, and other social science disciplines, such as Sociology, Area Studies, and Anthropology. C3 (yellow) includes categories related to business and agricultural economics. In cluster C4 (cyan) and C5 (brown), there are some disciplines with lower counts, such as Green and Sustainable Science and Technology, Engineering, and Physical Geography. Their occurrence shows the diversity of rural development studies. C6 (blue) includes the category with the highest co-occurrence count, Environmental Sciences and Ecology, which represents the most dominant research field in rural development. Other categories, such as Environmental Studies, Geography, and Urban Studies, make up cluster C7 (purple).

To reveal the changes in research orientations, we perform a chronological analysis using Alluvial Generator. Each flow represents one category and depicts the continuity of its centrality degree in the co-occurrence networks. As shown in Figure 5, Agriculture and Agricultural Economics and Policy are the dominant categories from 1971 to 1985, and they became less influential in the 1990s. However, they have gradually come back to the forefront since 2001. Business and Economics have been significant categories since 1971, especially from 2001 to 2010. Public Administration and Planning and Development appeared in the period 1976-1980 and received more and more attention from scholars in the 1980s. Environmental Sciences and Ecology, along with Environmental Studies, began to occupy an important position since 1991 and they have made greater contributions than other categories since 2011. It can be observed from Figure 5 that new categories have emerged along with the evolution of the study. One of the most promising categories since 2001 is Green and Sustainable Science and Technology, which might imply the new direction of rural development research. 
Table 2. Top 30 categories with highest co-occurrence count.

\begin{tabular}{|c|c|c|c|c|c|c|c|}
\hline No. & Category & Count & Centrality & No. & Category & Count & Centrality \\
\hline \multirow[t]{6}{*}{$\mathrm{C} 1$} & Agriculture & 1357 & 0.38 & $\mathrm{C} 3$ & $\begin{array}{l}\text { Agricultural Economics \& } \\
\text { Policy }\end{array}$ & 385 & 0.06 \\
\hline & $\begin{array}{c}\text { Agriculture, } \\
\text { Multidisciplinary }\end{array}$ & 580 & 0.02 & & $\begin{array}{l}\text { Food Science \& } \\
\text { Technology }\end{array}$ & 145 & 0.00 \\
\hline & $\begin{array}{c}\text { Science \& Technology-Other } \\
\text { Topics }\end{array}$ & 494 & 0.06 & $\mathrm{C} 4$ & $\begin{array}{l}\text { Green \& Sustainable } \\
\text { Science \& Technology }\end{array}$ & 402 & 0.02 \\
\hline & Forestry & 227 & 0.01 & & Engineering & 133 & 0.17 \\
\hline & Agronomy & 212 & 0.02 & C5 & Geography, Physical & 83 & 0.05 \\
\hline & Energy \& Fuels & 144 & 0.04 & C6 & $\begin{array}{c}\text { Environmental Sciences \& } \\
\text { Ecology }\end{array}$ & 1903 & 0.27 \\
\hline \multirow[t]{7}{*}{$\mathrm{C} 2$} & Public Administration & 1305 & 0.06 & & Environmental Sciences & 955 & 0.17 \\
\hline & Planning \& Development & 1103 & 0.09 & & Ecology & 327 & 0.05 \\
\hline & Sociology & 511 & 0.07 & & $\begin{array}{l}\text { Biodiversity \& } \\
\text { Conservation }\end{array}$ & 71 & 0.00 \\
\hline & Social Sciences-Other Topics & 215 & 0.03 & & Biodiversity Conservation & 67 & 0.00 \\
\hline & Area Studies & 155 & 0.02 & $\mathrm{C} 7$ & Environmental Studies & 1239 & 0.08 \\
\hline & Anthropology & 87 & 0.02 & & Geography & 1162 & 0.01 \\
\hline & $\begin{array}{l}\text { Social Sciences, } \\
\text { Interdisciplinary }\end{array}$ & 86 & 0.00 & & Urban Studies & 157 & 0.02 \\
\hline \multirow[t]{2}{*}{$\mathrm{C} 3$} & Business \& Economics & 1164 & 0.16 & & $\begin{array}{c}\text { Regional \& Urban } \\
\text { Planning }\end{array}$ & 141 & 0.00 \\
\hline & Economics & 1022 & 0.13 & & Development Studies & 112 & 0.00 \\
\hline
\end{tabular}

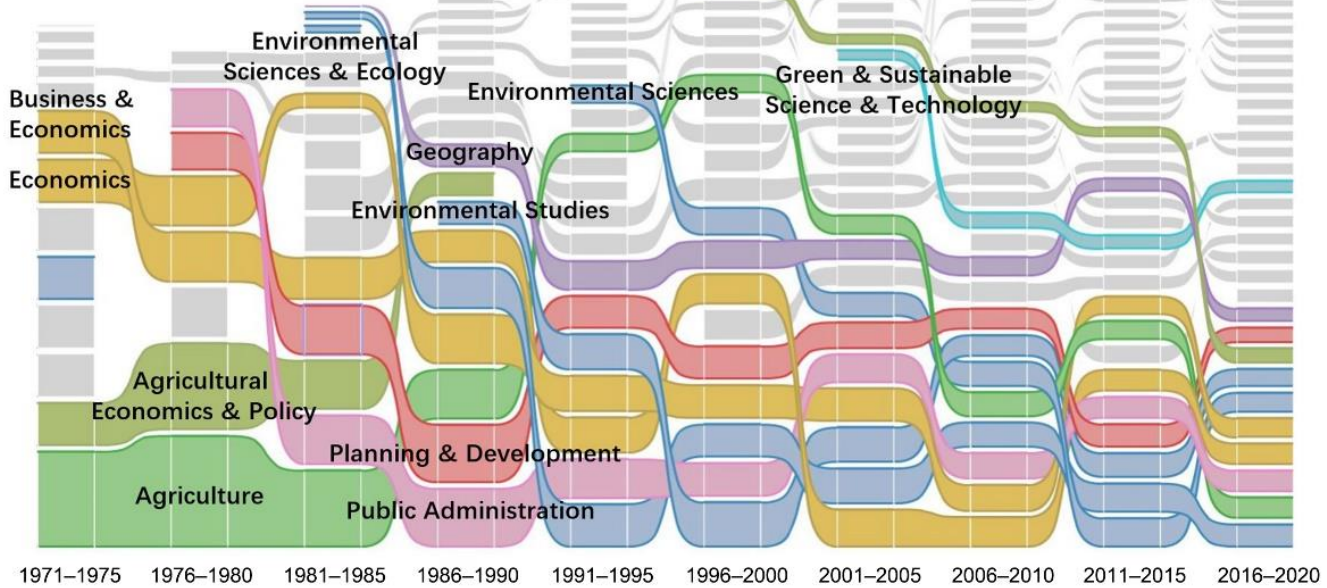

Figure 5. A timeline view of category co-occurrence network.

The results of category co-occurrence analysis reveal the fact that rural development research has become multidisciplinary and interdisciplinary between 1971 and 2020. In the earlier years, rural development mainly focused on agricultural issues. Then, various categories became involved including economics, public administration, environmental sciences, geography et al. However, no category manages to occupy the dominant position for more than 15 years, which suggests that the research focus of rural development has continued to shift during the past 50 years. The explosive growth in the number of categories also suggests that more and more scholars from diverse disciplines have devoted themselves to this field. Identifying the most influential authors over time is our next task. 


\subsection{Author Co-Citation Analysis}

The articles in DatasetALL have 234,689 references, which are written by more than 500,000 authors. The authors include both individuals and organizations. It is defined in CiteSpace that if two authors are simultaneously cited by an article, then they have a co-citation relationship. The author co-citation analysis can help us to evaluate the scientific performance of authors. The author that has the highest co-citation count and centrality degree can be identified as the major contributor in this research field. Table 3 shows the top ten highly cited authors. The names of organizations with asterisks are the alternative abbreviations. The information of the same author is combined into one in Table 3.

Table 3. Top 10 highly cited authors.

\begin{tabular}{|c|c|c|c|c|}
\hline Author & Full Name & Count & Centrality & Institution \\
\hline World Bank & World Bank & 631 & 0.11 & \\
\hline * World Bank & World Bank & 217 & 0.13 & \\
\hline Marsden T & Terry Marsden & 579 & 0.21 & $\begin{array}{l}\text { School of Geography and Planning, } \\
\text { Cardiff University, UK }\end{array}$ \\
\hline OECD & $\begin{array}{l}\text { Organization for Economic } \\
\text { Co-operation and Development }\end{array}$ & 378 & 0.04 & \\
\hline * OECD & $\begin{array}{l}\text { Organization for Economic } \\
\text { Co-operation and Development }\end{array}$ & 67 & 0.01 & \\
\hline Murdoch J & Jonathan L. Murdoch & 354 & 0.18 & $\begin{array}{c}\text { School of City and Regional } \\
\text { Planning, Cardiff University, UK }\end{array}$ \\
\hline FAO & $\begin{array}{l}\text { Food and Agriculture } \\
\text { Organization }\end{array}$ & 349 & 0.01 & \\
\hline * FAO & $\begin{array}{l}\text { Food and Agriculture } \\
\text { Organization }\end{array}$ & 116 & 0.00 & \\
\hline $\begin{array}{l}* * \text { EUROPEAN } \\
\text { COMMISSION }\end{array}$ & European Commission & 311 & 0.01 & \\
\hline $\begin{array}{c}\text { *EUR } \\
\text { COMM }\end{array}$ & European Commission & 46 & 0.00 & \\
\hline Van der $\mathrm{P}$ & Jan Douwe van der Ploeg & 280 & 0.04 & $\begin{array}{l}\text { Department of Sociology and } \\
\text { Anthropology of Development, } \\
\text { Wageningen University and } \\
\text { Research, The Netherlands }\end{array}$ \\
\hline Chambers R & Robert Chambers & 271 & 0.27 & $\begin{array}{l}\text { Institute of Development Studies, } \\
\text { University of Sussex, UK }\end{array}$ \\
\hline Goodman D & David Goodman & 207 & 0.03 & $\begin{array}{l}\text { Department of Environmental } \\
\text { Studies, University of California, } \\
\text { Santa Cruz, US }\end{array}$ \\
\hline Renting $\mathrm{H}$ & Henk Renting & 215 & 0.02 & $\begin{array}{l}\text { Urban Food Systems, Aeres } \\
\text { University of Applied Sciences, } \\
\text { The Netherlands }\end{array}$ \\
\hline
\end{tabular}

Among the top ten authors, four of them are international organizations, i.e., the World Bank, the OECD, the FAO, and the European Commission. Due to the different citation regulations of different journals, these organizations usually appear with two names, as shown in Table 3. The result shows that international organizations are active participants in the field of rural development research. The World Bank has funded numerous rural development programs worldwide since the last century. Rural development has been defined as "a strategy designed to improve the economic and social life of a specific group of people-the rural poor" in a World Bank sector paper [1]. This definition has implied the focus and aims of the work of the World Bank. The OECD tends to focus on the policies and governance of rural development. A framework "Rural Policy 3.0" 
has been created recently, aiming at helping national governments with promoting rural economic development. The main concern of FAO is food supply. The strategies of rural development are concentrated on ensuring food security, eliminating hunger, and enhancing agricultural productivity.

Information about the institutional affiliations of individual scholars is also shown in Table 3. It is worth noticing that the geographical distribution of the institutions is quite uneven. All these top researchers come from institutions in Europe and the United States. The top author from other countries is Long from China, ranking 18 on the list. It can be partly attributed to the publication language. Since more than $95 \%$ of the articles in DatasetALL are written in English, researchers in English-speaking countries and published in English are more likely to be recognized as the most influential authors. However, we should also admit that to some extent, rural development research is predominated by researchers from developed countries.

Author co-citation analysis can also give us an insight into the intellectual structure of rural development research. Figure 6 shows the co-citation network of 105 authors and reveals the interrelationships between them. The authors that share the theoretical or empirical similarities are located close to each other on the map and grouped into one cluster. As shown in Figure 6, authors including Marsden, Murdoch, van der Ploeg, Goodman, and Renting are closely related in the middle of the map. Chambers and the World Bank are located on the left side of the map, while a group of Chinese authors are on the right side.

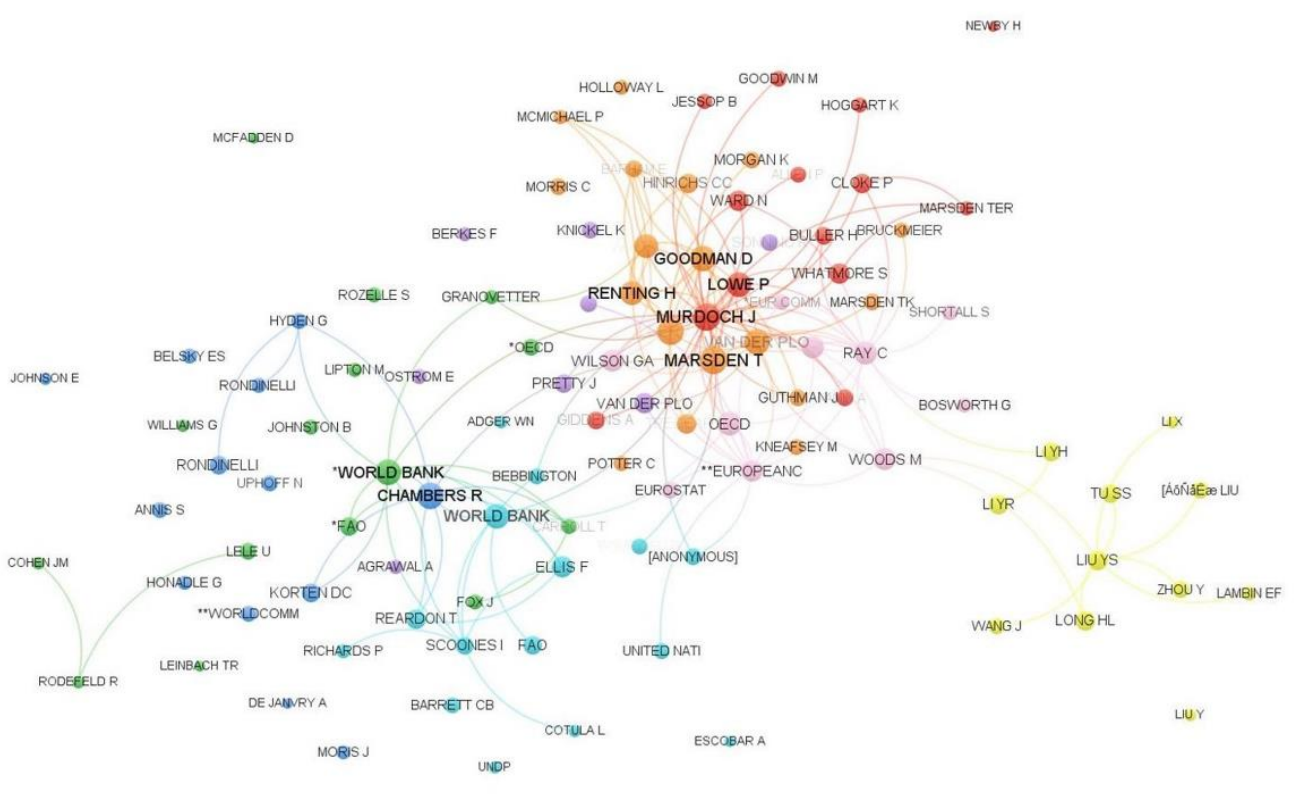

Figure 6. Author co-citation network.

Figure 7 illustrates the timeline view of the author co-citation network. The top ten authors are presented as a flow with a different color. The period in which the authors are highly cited can be observed from this graph.

Chambers and the World Bank were the major contributors to rural development research before 2000. As mentioned above, the World Bank announced a definition in 1975 and pointed out that attention should be paid especially to the "rural poor". Chambers has developed this idea by identifying "small-scale farmers, tenants and the landless" as the target group [2]. He studies the lives of farmers and reveals the nature of rural poverty from dimensions including deprivation, vulnerability, and powerlessness. He also 
introduced the concept of Participatory Rural Appraisal (PRA) as an approach for rural development [31].

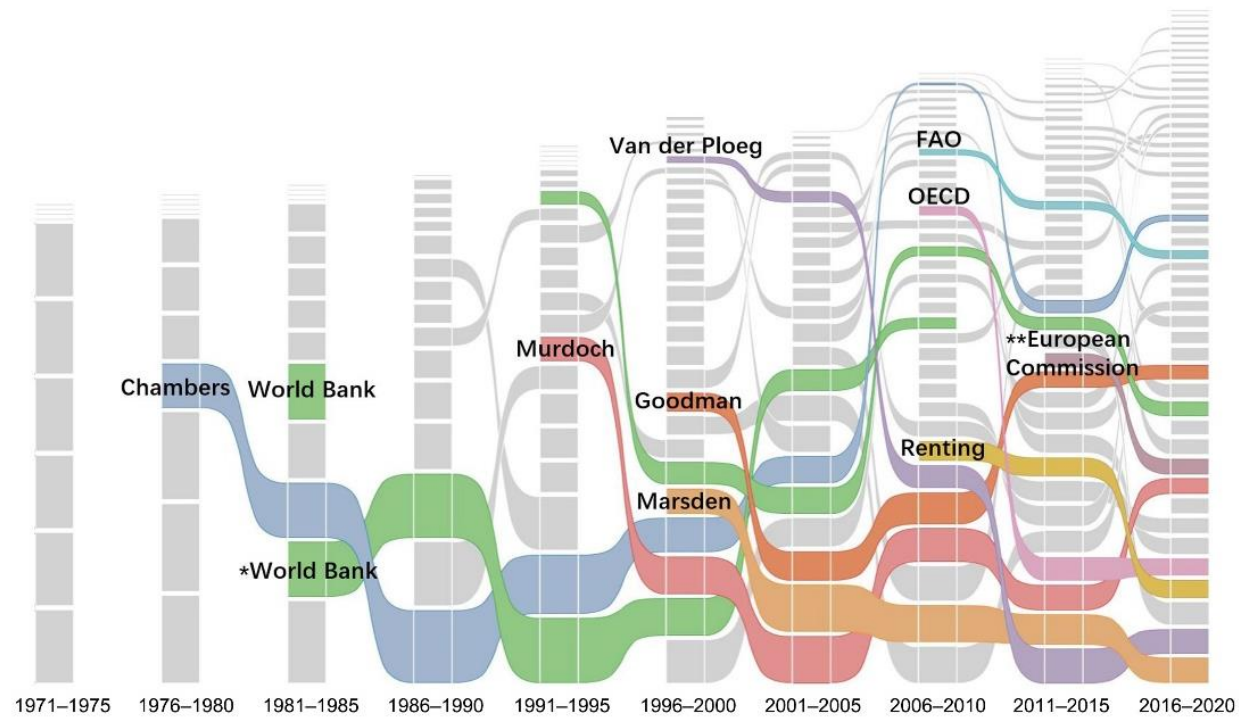

Figure 7. A timeline view of author co-citation network.

Marsden from the School of Geography and Planning, Cardiff University has a great number of publications and shows a continuing impact since 1991. His interdisciplinary research covers various fields including rural geography, rural sociology, planning et al. $\mathrm{He}$ is also interested in agricultural issues, such as the socio-economic restructuring of agriculture and agrifood chains and networks [32-34]. One of the great contributions that Murdoch makes is that he has fully developed the network theory in the rural development study. The actor-network theory has been widely applied both in the geographical analysis [35] and the investigation of food supply chains [36]. The network concept is also employed to provide a new paradigm of rural development [37]. Since 2000, van der Ploeg began to receive more citations. With a degree in agricultural engineering from Wageningen University, he specializes in agrarian sociology and economics [38]. Goodman and Renting are among the most influential authors in the past 20 years. They share the same research focus on food supply chains and alternative food networks $[39,40]$.

\subsection{Reference Co-Citation Analysis}

DatasetALL contains 6968 articles with 234,689 references. These references include books, journal articles, conference papers et al. If two references are both cited in one article, then they are co-cited. Reference co-citation analysis examines the citation frequencies. Then, we select the top 50 references every year to explore the intellectual structure of these references. Table 4 lists the top five highly cited references with information about their authors and journals.

What the four articles have in common is that they are all published in the 2000s, written by European scholars, and focus on food and agriculture issues. From the titles, we can infer that "alternative food network", "embeddedness" and "multifunctional agriculture" are topics in which researchers are interested. Renting et al. suggest that the "creation, operation and evolution" of alternative food networks is "the key dimensions of new rural development patterns" and the development of short supply chains contributes to the transitions in rural Europe [40]. Marsden and Sonnino critique the UK policies and emphasize the importance of "agricultural multifunctionality" in achieving sustainable rural development [34]. Winter explores the conflict between quality in agrifood and defensive localism and suggests that the turn to local food may be more promising in the future [41]. Murdoch et al. also discuss the relationship between quality, nature, and local embeddedness. Actor-network theory and conventions theory are employed to analyze 
the food supply chain in Wales [36]. The fourth article in Table 4 is the only one concerning rural development issues outside Europe. This article analyzes the "village-hollowing" phenomenon in rural China and examines the top-down implementation of land-use policy. Long et al. suggest that the lack of engagement with local actors has caused resistance to policy [42].

Table 4. Top 5 highly cited references.

\begin{tabular}{|c|c|c|c|c|}
\hline Author & Year & Title & Journal & Count \\
\hline $\begin{array}{c}\text { Renting, H., Marsden, T., \& } \\
\text { Banks, J. }\end{array}$ & 2003 & $\begin{array}{c}\text { Understanding Alternative Food } \\
\text { Networks: Exploring the Role of Short } \\
\text { Food Supply Chains in Rural } \\
\text { Development [40] }\end{array}$ & $\begin{array}{l}\text { Environment and } \\
\quad \text { Planning } A\end{array}$ & 81 \\
\hline Marsden, T., \& Sonnino, R. & 2008 & $\begin{array}{l}\text { Rural development and the regional } \\
\text { state: Denying multifunctional } \\
\text { agriculture in the UK [34] }\end{array}$ & Journal of Rural Studies & 63 \\
\hline Winter, M & 2003 & $\begin{array}{l}\text { Embeddedness, the new food economy, } \\
\text { and defensive localism [41] }\end{array}$ & Journal of Rural Studies & 61 \\
\hline $\begin{array}{c}\text { Long, H., Li, Y., Liu, Y., Woods, } \\
\text { M., \& Zou, J. }\end{array}$ & 2012 & $\begin{array}{c}\text { Accelerated restructuring in rural China } \\
\text { fueled by 'increasing vs. decreasing } \\
\text { balance' land-use policy for dealing } \\
\text { with hollowed villages [42] }\end{array}$ & Land Use Policy & 56 \\
\hline $\begin{array}{c}\text { Murdoch, J., Marsden, T., \& } \\
\text { Banks, J. }\end{array}$ & 2000 & $\begin{array}{l}\text { Quality, Nature, and Embeddedness: } \\
\text { Some Theoretical Considerations in the } \\
\text { Context of the Food Sector [36] }\end{array}$ & Economic Geography & 53 \\
\hline
\end{tabular}

\subsection{Keyword Co-Word Analysis}

We continue to explore the content of rural development research by analyzing the keywords of articles in DatasetALL. Each article contains two kinds of keywords: the author-given keywords, and the keywords from Keyword Plus, which are provided by Web of Science. Both keywords are chosen to summarize the core content of articles. Keyword co-word analysis examines the co-occurrence frequency of keywords. A total of 79 keywords are found in the result, and 77 keywords are displayed in Figure 8.

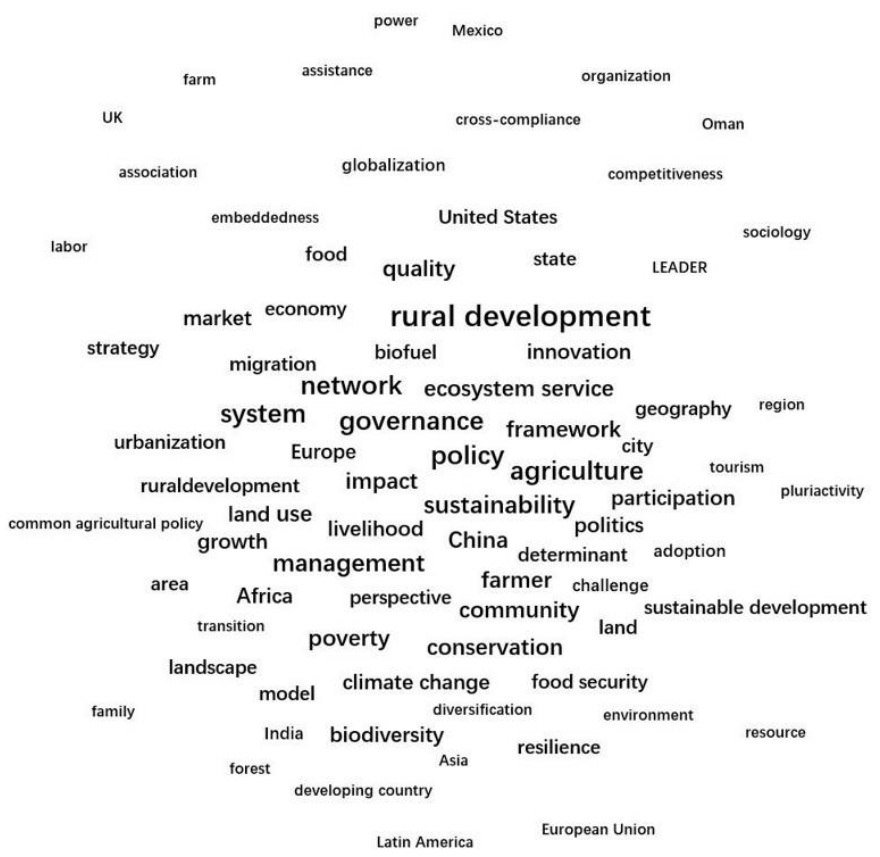

Figure 8. Keyword co-word network. 
The keywords can be divided into categories. Keywords that represent geographical areas are grouped into Category 2, and others in Category 1. Table 5 lists the top ten keywords in Category 1 and the top four keywords in Category 2. The words "rural development", "rural" and "development" are excluded from the list.

Table 5. Top 10 keywords and top 4 geographical keywords.

\begin{tabular}{cccccccc}
\hline & Keywords in Category 1 & Count & Centrality & & Keywords in Category 2 & Count & Centrality \\
\hline 1 & agriculture & 552 & 0.19 & 1 & China & 260 & 0.10 \\
2 & policy & 482 & 0.15 & 2 & Africa & 143 & 0.07 \\
3 & management & 399 & 0.05 & 3 & Europe & 72 & 0.01 \\
4 & system & 304 & 0.12 & 4 & & \\
5 & conservation & 271 & 0.13 & & & \\
6 & sustainability & 271 & 0.08 & & & \\
7 & impact & 268 & 0.06 & & & \\
8 & governance & 220 & 0.12 & & & \\
9 & poverty & 193 & 0.06 & & & \\
10 & network & 179 & 0.05 & & &
\end{tabular}

The word that has the highest count and centrality degree is "agriculture". "Policy", "management", "system", and "conservation" rank from second to fifth. Other crucial keywords include "sustainability", "impact", "governance", "poverty", "network" et al. In Category 2, "China", with the highest co-word count of 260, ranks first, followed by "Africa" in the second position. "Europe" and "India" rank third and fourth, respectively. These top keywords indicate the research areas that receive more attention from worldwide researchers.

Figure 9 presents the linkage between keywords in Category 2 and keywords in Category 1. It is interesting to notice that different countries and regions are linked with diverse keywords. Keywords linked to "China" include "policy", "impact", "governance", "sustainability", "ecosystem service" et al. "Africa" is related to "poverty", "agriculture", "sustainability", "policy", "farmer" et al. "Europe" is associated with "network", "land use", "management", "policy", "economy" et al. "India" is connected with keywords such as "poverty", "management", "conservation", "community", and "growth". The result implies that different regions and counties are facing various problems and challenges in rural development. The research focus and approaches of scholars also vary when embedded in diverse contexts.
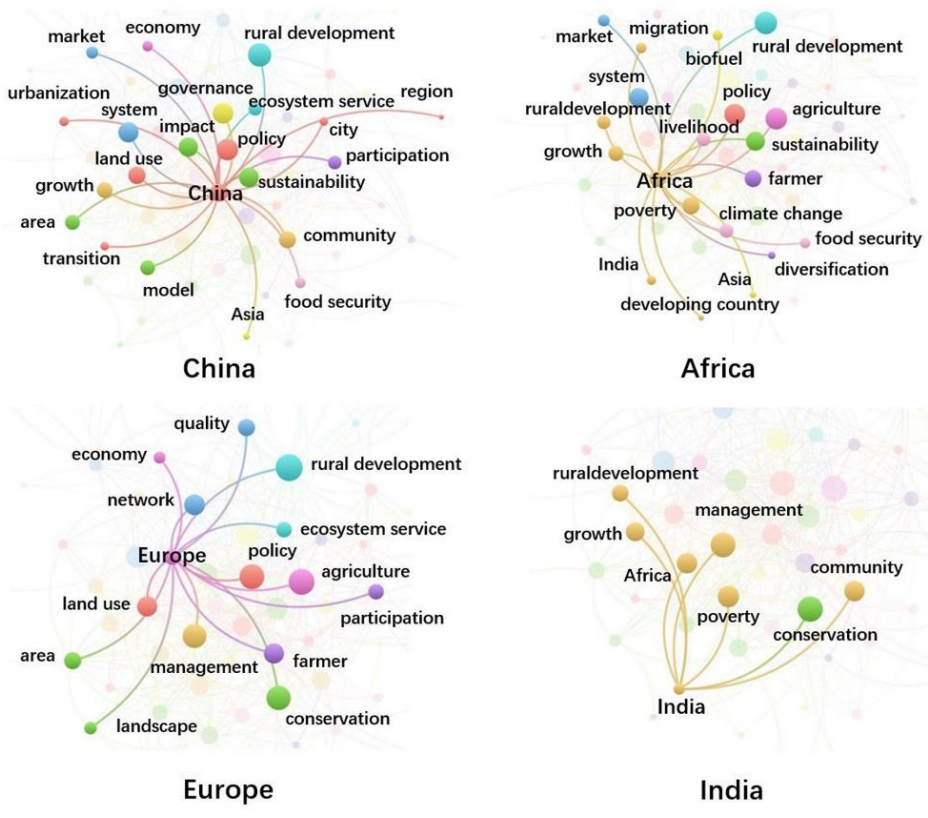

Figure 9. The linkage between keywords in Category 2 and keywords in Category 1. 
The burst detection identifies keywords that have more counts in co-word analysis in certain periods. Figure 10 shows the top 30 keywords with the strongest burst. The period during which these keywords are more popular among scholars is depicted in red. The emerging trends in rural development research can be identified by analyzing the burst duration of different keywords.

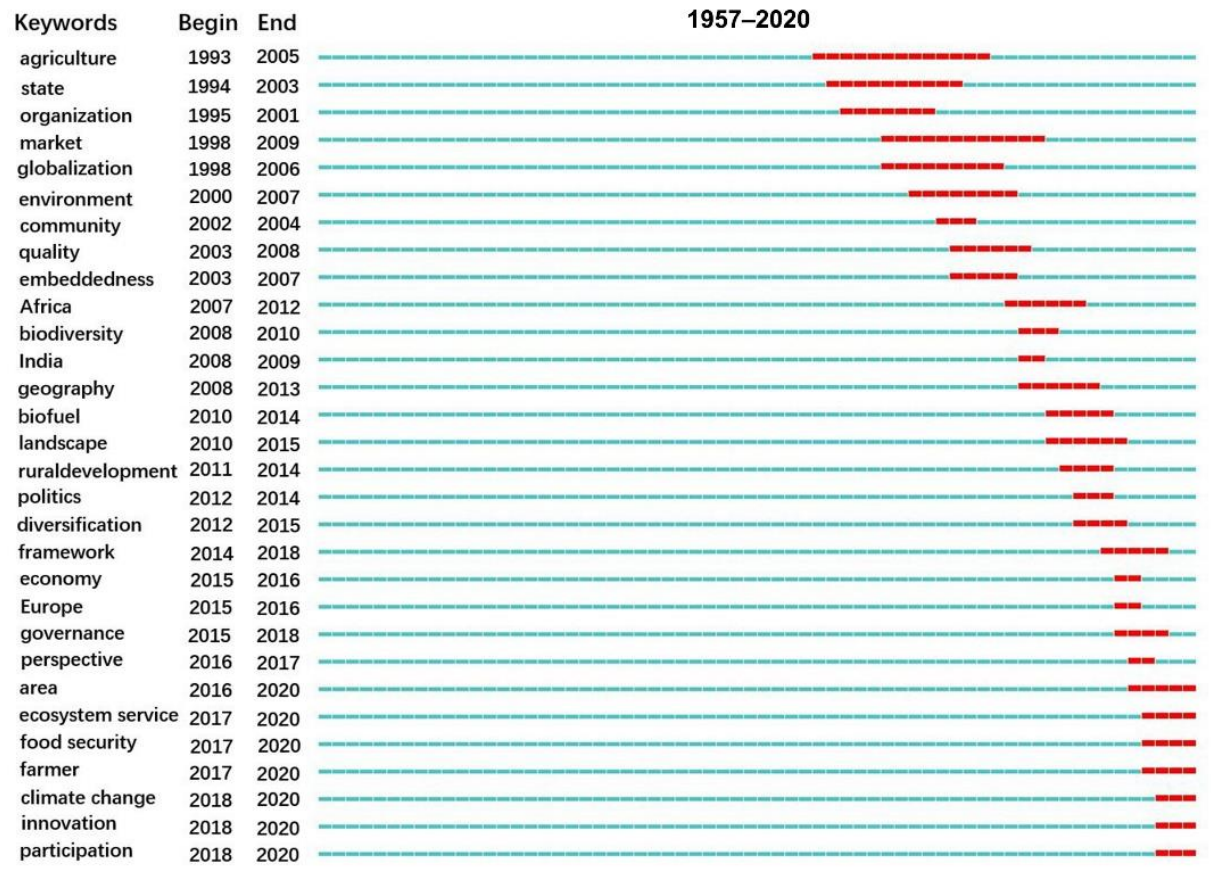

Figure 10. The top 30 keywords with the strongest burst.

As presented in Figure 10, "agriculture" and "market" have the longest burst duration of more than ten years. It suggests these topics are the conventional issues related to rural development. Since the 1990s, scholars have shown interests in the topic such as "state", "organization" and "globalization". In the 2000s, "environment", "community", "embeddedness" and "biodiversity" have received the attention of researchers. After 2010, scholars have paid close attention to rural issues related to "biofuel", "landscape" "diversification" and "governance". The recent topics which are highly cited until 2020 include "ecosystem service", "food security", "farmer", "climate change", "innovation", and "participation".

\section{Discussion}

As the major findings have been described in Section 3, their implications are summarized as follows.

The first article from our dataset is found in 1957. Articles concerning rural development are limited after that for many years. After 1985, the number of articles began to increase, which may be attributed to the publication of two crucial journals in this research field, Land Use Policy in 1984 and the Journal of Rural Studies in 1985. During the last decade, the number increased rapidly and reached 513 in 2020. The continuous growth of yearly output proves that rural development issues have been receiving consistent interest from scholars. It is worth noting that while the urbanization process has been a global phenomenon and urban studies have become popular in recent years, rural studies have not been ignored. Many studies have been conducted concerning the impact of urbanization on the spatial, social, economic, and environmental development of rural areas. We argue that the issues of urban and rural development should not be separated from each other and the problems can only be solved when the urban and rural are regarded as a whole. 
The articles are published in a variety of journals. The most influential journals include the Journal of Rural Studies, World Development, Sociologia Ruralis et al. The diversity of journals implies that many disciplines are involved. The results of category co-occurrence analysis suggest that rural development research is rooted in the study of agriculture in the 1970s and the early 1980s. Since then, it has drawn the attention of scholars from diverse disciplines, including but not limited to economics, environmental studies, public administration, planning, geography, and green and sustainable science. Rural development research evolves towards multidisciplinary and interdisciplinary work, which brings both opportunities and challenges. With more and more scholars engaging in the research from various perspectives, the spectrum of rural development becomes wider, and the complexity and diversity of rural development could be better understood. Moreover, abundant research methods and approaches from other disciplines could be employed in rural development research. Novel ideas could be inspired by cooperation and communication between scholars from different research fields. Meanwhile, challenges also exist. The difference in academic backgrounds could produce obstacles in the dialogues between scholars. It also explains why there is no consensus on the definition. The cooperation might fail when they have a different interpretation of the contexts, the problems, or the goals of rural development. Contradictory advice might be given, which increases the difficulty in making rural development strategies. Hence, the concepts, methods, or approaches that could help to bridge gaps and transcend the boundaries between disciplines are needed. "Sustainability" seems to be one of the emerging concepts in rural development in recent years, which could be the common goal of scholars, but it is still interpreted differently from diverse disciplinary perspectives. Exploring and identifying more concepts such as "sustainability" in rural development could be helpful for further study.

The author co-citation analysis points out that international organizations such as the World Bank, OECD, FAO, and European Commission play important roles not only in practice but also in the academic field. The most influential authors include Marsden, Murdoch, van der Ploeg, Chambers et al. It is worth pointing out that they all come from institutions in Europe and the United States. There are no authors from Africa or Asia among the top ten. The results indicate that scholars from Europe produce a significant share of articles and have a noticeable influence in the international academic community. Hence, many fundamental theories in rural development are formed based on their empirical research in Europe, especially in the United Kingdom. For example, British scholars started to discuss the definitions of "rural" and the index of "rurality" in the 1970s [43-45]. Marsden's theories on food supply chains and multifunctional agriculture also come from case studies in the UK $[33,34]$.

We also learn from the keyword co-word analysis that China and Africa are the top two regions in which scholars are most interested. The comparison implies that scholars from Europe and the US have undertaken a lot of research in developing countries. This is an interesting phenomenon, which could bring both benefits and troubles. We believe that international cooperation concerning rural development between scholars or countries could be meaningful to both sides. The developing countries could learn from the experience of other countries and examine their problems from other perspectives. However, being embedded in foreign contexts can be challenging for both scholars and practitioners. First, the development processes of rural areas in different regions are unique and initiated by different groups of stakeholders. In Europe, farmers and their networks can be regarded as the "engine" of rural development processes, while in Brazil, social movements play the same role. However, in China, the state controls the direction of rural development by the implementation of various policies and strategies [46]. Moreover, there are huge risks of misunderstanding and misinterpretation when talking about concepts and theories concerning rural development. The results of keyword co-word analysis show that "China" has a strong linkage with the word "governance", and "Africa" with "poverty". We think that there could be great differences in the interpretation of "governance" and "poverty" between Western scholars and people in China and Africa. The development 
theories which are developed in Western countries could also fail with totally different historical backgrounds and cultural traditions. After conducting case studies in East Asia and Latin America, Gereffi points out that the prior generalizations from some theoretical perspectives are "too sweeping" and development theory should "incorporate and integrate the global, national, and local levels of analysis" [47]. Finally, different regions can take different development approaches. We could not agree with Shortall, who claims that "the form of rural development throughout the European Union" reflects the "global trends" [6]. The European perspectives of rural development could not represent others in the world. Gerschenkron suggests that the industrialization processes show differences in both speed and character in different countries. The development of "backward countries" may not follow the road of "advanced countries". On the contrary, it may "by the very virtue of its backwardness, tend to differ fundamentally" [48]. Therefore, we argue that the complex contexts and diverse interpretations of rural development should never be neglected. The analysis results in this paper are generated from a dataset that consists of articles mostly by English-speaking authors. We admit that this is one of the limitations of this research and we are also aware that there are numerous excellent studies written in other languages and are published in other journals, which are not included in the dataset. If we need deep insight into the rural development in China, we need to analyze the articles written by Chinese scholars and published in China. Furthermore, a case study is needed. It could be the next step of our research.

The burst detection of keywords shows that rural development research is dynamic, and the topics have evolved over the past few decades. There is no consistent dominance of a topic, which proves the complexity of conceptualizing rural development throughout time. It can be predicted that more and more studies will take diverse approaches which integrate multiple dimensions and keywords concerning rural development will continue to be updated in the future.

\section{Conclusions}

In this paper, we apply a bibliometric and visual analysis to rural development research. The aim is to analyze the knowledge domain and its evolution. The study provides an example of conducting a literature review with a quantitative approach. We suggest that literature can be treated as datasets that contain various pieces of information. Data are downloaded from the database Web of Science. The period covers from 1957 to 2020. After the search, retrieval, and pre-processing process assisted by HistCite ${ }^{\mathrm{TM}}$ and CiteSpace, the dataset for analysis is formed, consisting of 6968 articles. The analysis units include journals, categories, authors, references, and keywords. Co-occurrence and co-citation analysis are conducted, and the results are exported in the format of networks. Science mapping methods help us to interpret these networks and understand how these units are connected. The cluster views, which illustrate the spatial structures of networks, are displayed in VOSviewer. Timeline views show the flow of networks throughout time and are generated in Map and Alluvial Generator. This research methodology can be employed by scholars to explore the landscape of other studies. It can be useful to have a quick overview, especially when one comes into contact with a new field. The thematic and chronological analysis of publications also helps the scholars to identify the frontiers and the gaps in the research fields.

We analyze the trends of publications, explore the discipline distribution, identify the most influential journals, authors, and articles, and detect the top keywords at different times. The results can help scholars and practitioners to have a better understanding of the intellectual structure of rural development research and its evolution. It can be concluded that rural development research has become more and more multidisciplinary and interdisciplinary and will attract the attention of scholars from a variety of research fields. The issues concerning rural development have continued to change over the past decades, which reflects the dynamics and complexity of rural contexts worldwide. Since there are significant differences in the socio-economic, environmental, and political development 
between different regions at different times, we suggest that it is only feasible to analyze the pattern of rural development when focusing on one region with a consistent context. Hence, a case study is needed for further research.

Author Contributions: Conceptualization, Y.L.; methodology, Y.L.; software, Y.L.; formal analysis, Y.L.; investigation, Y.L.; resources, Y.L.; data curation, Y.L.; writing-original draft preparation, Y.L.; writing-review and editing, Y.L. and W.T.d.V.; visualization, Y.L.; supervision, W.T.d.V. All authors have read and agreed to the published version of the manuscript.

Funding: This research received no external funding.

Data Availability Statement: All data used in this study are available by request from the corresponding author (ying.lu@tum.de).

Conflicts of Interest: The authors declare no conflict of interest.

\section{References}

1. Rural Development: Sector Policy Paper. Available online: http://documents.worldbank.org/curated/en/688121468168853933 /Rural-development-sector-policy-paper (accessed on 7 May 2019).

2. Chambers, R. Rural Development: Putting the Last First; Routledge: London, UK, 1983; pp. 2-27.

3. Copp, J.H. Rural sociology and rural development. Rural Sociol. 1972, 37, 515-533.

4. Harriss, J. Rural Development: Theories of Peasant Economy and Agrarian Change; Routledge: London, UK, 1982; pp. 1-409.

5. Van der Ploeg, J.D.; Renting, H.; Brunori, G.; Knickel, K.; Mannion, J.; Marsden, T.; De Roest, K.; Sevilla-Guzmán, E.; Ventura, F. Rural development: From practices and policies towards theory. Sociol. Rural. 2000, 40, 391-408. [CrossRef]

6. Shortall, S. Social or economic goals, civic inclusion or exclusion? An analysis of rural development theory and practice. Sociol. Rural. 2004, 44, 109-123. [CrossRef]

7. Wang, J.; Liu, Z. A bibliometric analysis on rural studies in human geography and related disciplines. Scientometrics 2014, 101, 39-59. [CrossRef]

8. Ellis, F.; Biggs, S. Evolving themes in rural development 1950s-2000s. Dev. Policy Rev. 2001, 19, 437-448. [CrossRef]

9. International and Local Approaches to Rural Development. Available online: http://www.phuhlisani.com/oid\%5Cdownloads\% 5C26082009\%20RD\%20literature\%20review\%2001.pdf (accessed on 10 June 2019).

10. Pritchard, A. Statistical bibliography or bibliometrics. J. Doc. 1969, 25, 348-349.

11. Fairthorne, R.A. Empirical hyperbolic distributions (Bradford-Zipf-Mandelbrot) for bibliometric description and prediction. J. Doc. 1969, 25, 319-343. [CrossRef]

12. Hawkins, D.T. Unconventional uses of on-line information retrieval systems: On-line bibliometric studies. J. Am. Soc. Inform. Sci. 1977, 28, 13-18. [CrossRef]

13. Sengupta, I.N. Bibliometrics: A bird's eye view. IASLIC Bull. 1985, 30, 167-174.

14. Broadus, R. Toward a definition of "bibliometrics". Scientometrics 1987, 12, 373-379. [CrossRef]

15. Diodato, V.P. Dictionary of Bibliometrics; The Haworth Press: New York, NY, USA, 1994; pp. 1-168.

16. White, H.D.; McCain, K.W. Visualizing a discipline: An author co-citation analysis of information science, 1972-1995. J. Am. Soc. Inform. Sci. 1998, 49, 327-355.

17. Pritchard, A.; Wittig, G.R. Bibliometrics: A Bibliography and Index; ALLM Books: Watford, UK, 1981; pp. 3-8.

18. Van Raan, A. Advanced bibliometric methods as quantitative core of peer review based evaluation and foresight exercises. Scientometrics 1996, 36, 397-420. [CrossRef]

19. Chen, C. CiteSpace II: Detecting and visualizing emerging trends and transient patterns in scientific literature. J. Am. Soc. Inform. Sci. Tech. 2006, 57, 359-377. [CrossRef]

20. Silva, E.G.; Teixeira, A.A. Surveying structural change: Seminal contributions and a bibliometric account. Struct. Chang. Econ. Dyn. 2008, 19, 273-300. [CrossRef]

21. Liao, H.; Tang, M.; Luo, L.; Li, C.; Chiclana, F.; Zeng, X.J. A bibliometric analysis and visualization of medical big data research. Sustainability 2018, 10, 166. [CrossRef]

22. Small, H. Update on science mapping: Creating large document spaces. Scientometrics 1997, 38, 275-293. [CrossRef]

23. Small, H. Visualizing science by citation mapping. J. Am. Soc. Inform. Sci. 1999, 50, 799-813. [CrossRef]

24. Cobo, M.J.; López-Herrera, A.G.; Herrera-Viedma, E.; Herrera, F. Science mapping software tools: Review, analysis, and cooperative study among tools. J. Am. Soc. Inform. Sci. Tech. 2011, 62, 1382-1402. [CrossRef]

25. Garfield, E.; Pudovkin, A.I.; Istomin, V.S. Mapping the output of topical searches in the Web of Knowledge and the case of Watson-Crick. Inf. Technol. Libr. 2003, 22, 183-188.

26. Van Eck, N.; Waltman, L. Software survey: VOSviewer, a computer program for bibliometric mapping. Scientometrics 2010, 84, 523-538. [CrossRef]

27. Rosvall, M.; Bergstrom, C.T. Maps of random walks on complex networks reveal community structure. PNAS 2008, 105, 1118-1123. [CrossRef] 
28. Rosvall, M.; Bergstrom, C.T. Mapping change in large networks. PLoS ONE 2010, 5, e8694. [CrossRef]

29. Nyerere, J.K. Socialism and rural development. Mbioni 1967, 4, 2-46.

30. World Cities Report 2020: The Value of Sustainable Urbanization. Available online: https://unhabitat.org/sites/default/files/20 20/10/wcr_2020_report.pdf (accessed on 13 March 2021).

31. Chambers, R. Participatory rural appraisal (PRA): Analysis of experience. World Dev. 1994, 22, 1253-1268. [CrossRef]

32. Marsden, T. From post-productionism to reflexive governance: Contested transitions in securing more sustainable food futures. J. Rural Stud. 2013, 29, 123-134. [CrossRef]

33. Marsden, T.; Banks, J.; Bristow, G. Food supply chain approaches: Exploring their role in rural development. Sociol. Ruralis 2000, 40, 424-438. [CrossRef]

34. Marsden, T.; Sonnino, R. Rural development and the regional state: Denying multifunctional agriculture in the UK. J. Rural Stud. 2008, 24, 422-431. [CrossRef]

35. Murdoch, J. The spaces of actor-network theory. Geoforum 1998, 29, 357-374. [CrossRef]

36. Murdoch, J.; Marsden, T.; Banks, J. Quality, nature, and embeddedness: Some theoretical considerations in the context of the food sector. Econ. Geogr. 2000, 76, 107-125. [CrossRef]

37. Murdoch, J. Networks-A new paradigm of rural development? J. Rural Stud. 2000, 16, 407-419. [CrossRef]

38. Van der Ploeg, J.D. Rural sociology and the new agrarian question: A perspective from The Netherlands. Sociol. Ruralis 1993, 33, 240-260. [CrossRef]

39. Goodman, D. Rural Europe redux? Reflections on alternative agro-food networks and paradigm change. Sociol. Ruralis 2004, 44, 3-16. [CrossRef]

40. Renting, H.; Marsden, T.K.; Banks, J. Understanding alternative food networks: Exploring the role of short food supply chains in rural development. Environ. Plan A 2003, 35, 393-411. [CrossRef]

41. Winter, M. Embeddedness, the new food economy and defensive localism. J. Rural Stud. 2003, 19, 23-32. [CrossRef]

42. Long, H.; Li, Y.; Liu, Y.; Woods, M.; Zou, J. Accelerated restructuring in rural China fueled by 'increasing vs. decreasing balance' land-use policy for dealing with hollowed villages. Land Use Policy 2012, 29, 11-22. [CrossRef]

43. Cloke, P. An index of rurality for England and Wales. Reg. Stud. 1977, 11, 31-46. [CrossRef]

44. Cloke, P.; Edwards, G. Rurality in England and Wales 1981: A replication of the 1971 index. Reg. Stud. 1986, 20, 289-306. [CrossRef]

45. Halfacree, K.H. Locality and social representation: Space, discourse and alternative definitions of the rural. J. Rural Stud. 1993, 9, 23-37. [CrossRef]

46. Van der Ploeg, J.D.; Ye, J.Z.; Schneider, S. Rural development: Actors and practices. In Constructing a New Framework for Rural Development, 1st ed.; Milone, P., Ventura, F., Ye, J.Z., Eds.; Emerald Group Publishing: Bingley, UK, 2015; Volume 22, pp. 17-30.

47. Gereffi, G. Rethinking development theory: Insights from East Asia and Latin America. In The Globalization and Development reader, 2nd ed.; Roberts, J.T., Hite, A.B., Chorev, N., Eds.; Blackwell Publishing: West Sussex, UK, 2015; Volume 2, pp. 169-190.

48. Gerschenkron, A. Economic backwardness in historical perspective. In The Globalization and Development Reader, 2nd ed.; Roberts, J.T., Hite, A.B., Chorev, N., Eds.; Blackwell Publishing: West Sussex, UK, 2015; Volume 1, pp. $62-78$. 